\title{
HUMAN DETECTION ROBOT IN FLOOD
}

\section{AMRUTHA M S, SMERA KURIAN, ANGEL JOSHNA JOSE, ARUN KRISHNA P A \& DR. GNANA KING}

Sahrdaya College of Engineering and Technology, Kodakara, India

ABSTRACT
Flood is the very common disaster that is being facing in these days. Heavy rainfall with rise of water level in dams, rivers
and other water resources have lead to flood in all parts of India. Over two lakh people have been directly affected by
flood. The unexpected flood leads to missing of people. Finding out people who are trapped in under water is difficult and
risky job for human. This will lead to delay and may cause the loss of life of people. As this disaster is common in every
year, we have to be taking a better solution for this problem. To overcome this we have come up with an idea to rescue
people who are trapped. We have planned to make a robot which move under water. It will sense and detects the human
under water. A sensor will be placed to identify the position of man under water. Thus robot helps in rescuing man from
flood.
KEYWORDS: Arduino Uno, Rasperri pi, GPS, L293D Motor

Received: Jun 06, 2020; Accepted: Jun 26, 2020; Published: Aug 25, 2020; Paper Id.: IJMPERDJUN2020879

\section{INTRODUCTION}

Recently majority areas of the world are affected by different natural calamities. The most common disaster is flood. And it takes of many lives. Recent floods in 2018 and 2019 have affected more than three forth of the population of India. Floods causes destruction and thousands of life s were lost. Many people were trapped under water for many days. Floods will be affected in vast area. During flood detection of human by rescue team is very difficult task. It takes a lot of time to find out human from the affected area. Millions of people need to be replaced during the flood time. It becomes cumbersome task for all the workers. Due to this a lot of life was lost. Many remote areas will get isolated without proper communication. All the mobile networks will be damaged during floods and this will lag the time to save the people who are trapped. Proper rescue team can only save the life of people who are trapped in such a disaster.

Fast and furious decision must be taken by rescue team and hence the people to safe location at their own risk. So our project proposes a mobile rescue robot that moves in flood affected area and help in identifying the live people who are trapped in water. A mobile In such situations, rescue system must take fast decisions under pressure, and try to get victims to safe location at their own risk. So the project proposes a mobile rescue robot that moves in a disastrous area and helps in identifying the live people and rescue operations. A robot is a reprogrammable, multifunctional manipulator designed to move materials, parts, tools or specialized devices through variable programmed motions for the performance of a variety of tasks. For overcoming all these problems, we have found out a proposal a rescue robot for human detection which moves in the flood affected area and help finding out the live people who are trapped under water. With proper detection in time, life can be saved. 


\section{LITERATURE REVIEW}

In these days new technology and increasing computer capacity robots are obtaining in our daily life. By the improvement of the technology they are capable of performing many task. Different kind of robots are being used for several purposes such as hospital purposes and cleaning rooms. More smart and intelligent robots must move towards autonomy: they are having the ability to perform task without human operations. Mainly four types of rescue robots based on that it is classified to four types: Unmanned Ground Vehicles (UGV), Unmanned Aerial Vehicle (UAV), Unmanned Underwater Vehicle (UUV), and Unmanned Surface Vehicle (USV).

From the built in LED (Light Emitting Diode) connected to digital pin 13. Motion detection is done by passive Infrared sensor module. Motion detection is work from $5 \mathrm{v}$ to $9 \mathrm{v}$ DC and gives digital output. It also having a pyro electric sensor that recently developed solutions for the safe Research Article Volume 7 Issue No.4 it can detect motion by measuring change in the infrared levels emitted by the presence of the objects. Obstacle detector is mainly using to detect obstacles. For transmitting the alert messages it is using RF transmitter and Receiver. The main aim for which the robot was designed is to detect the human's presence during floods. We are Using a PIR sensor it will detect the presence of the humans and alert messages is sends to rescue teams.

Non-immersive virtual reality systems, are the least immersive implementation of virtual reality techniques.

Human detection robot detects humans who are trapped in water during floods from buildings and from floating water areas. Our robot is a moving robot which will move in water. We all that it's a very long process to find out the people in water and very time consuming process for the rescue team. The robot will move in water and ultrasonic sensor is used. By the help of sensor it will move automatically. A rasperipi is used for image detection. A camera is fixed for capturing the images. when a human is detected a message containing the location of people where they are trapped will be send to rescue team it automatically move by help of sensor and detection occurred. When a human is detected it will send that location to the rescue team by GPS. Gps will tracks the exact location and send to rescue team.

\section{SYSTEM DESIGN}

\section{Arduino Uno}

An open-source microcontroller board based on the Microchip A Tmega 328 P microcontroller. Arduino Uno was developed by Arduino.cc. It consists of group of digital and analog input/output (I/O) pins. It can be interfaced to various other expansion boards and to other circuits. Arduino Uno consists of 6 Analog pins, 14 Digital pins and programmable with the Arduino IDE through a type B USB cable.

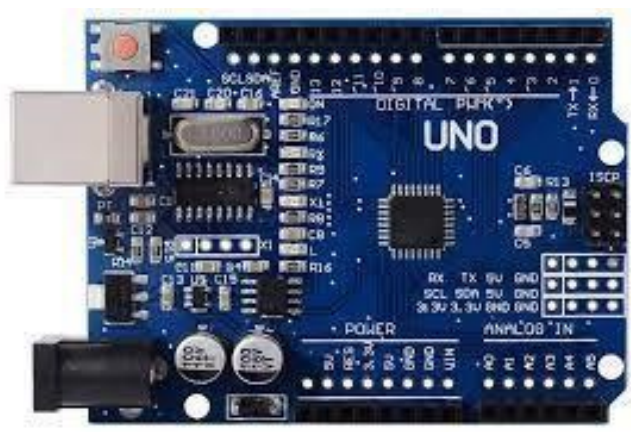

Figure 1: Arduino Uno. 


\section{Rasperry Pi}

A series of small single board computers developed by the Rasperry Pi Foundation. It is also used in research project like weather monitoring as it is low cost and portable. Rasperry pi does not include peripheral or cases.

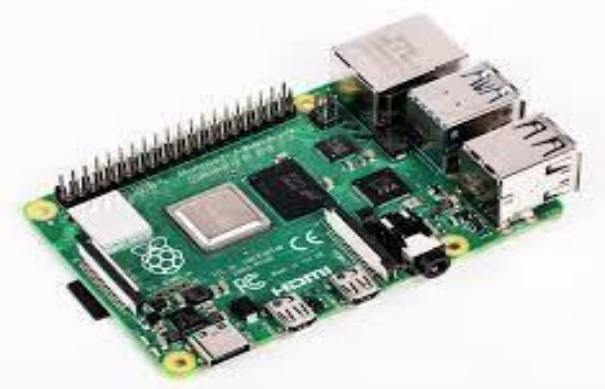

Figure 2: Rasperry Pi.

\section{Ultrasonic Sensor}

A sonar is used in ultrasonic sensor to determine distance of an object. It offers high non-contact range detection with high accuracy. It have a transmitter that transmit ultrasonic wave that travels in air. And get reflected back towards the sensor. Receiver module will observe the reflected wave.

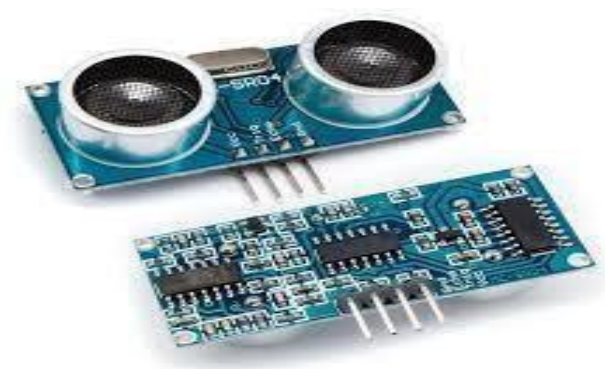

Figure 3: Ultrasonic Sensor.

\section{GPS Module}

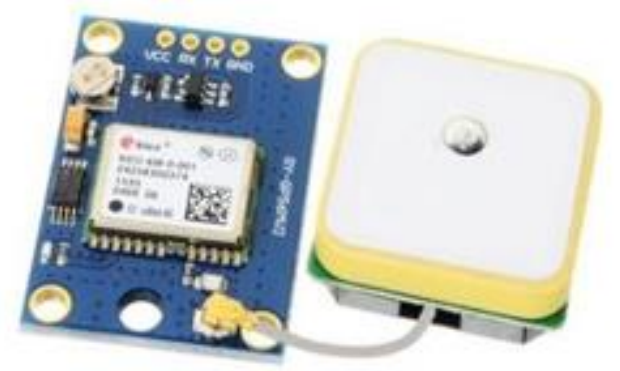

Figure 4: GPS Module.

A satellite navigation system which is used to determine the ground position of an object. GPS is used to track the receivers location using three satellites. It provides high accuracy.

\section{L293D Motor}

A popular 16-Pin Motor Driver IC. L293D is mainly used to drive motors. Two DC motors can be driven by a single L293D at same time. The direction of motors can also be controlled independently. 


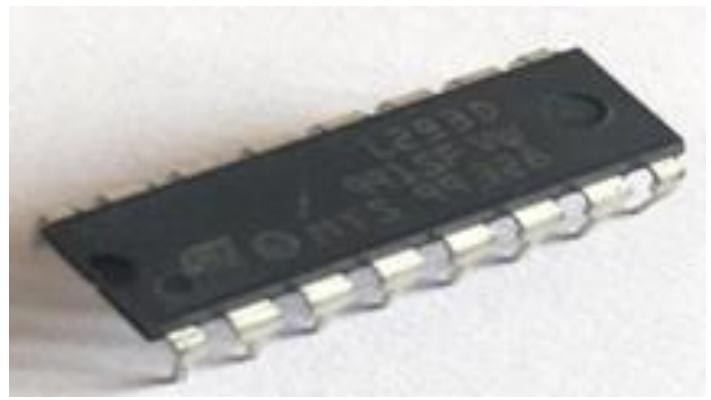

Figure 5: L293D Motor.

\section{Camera}

A webcam is a video camera that feeds or streams an image or video in real time to or through a computer to a computer network, such as the Internet. Webcams can be used during a video chat session involving two or more people, with conversations that include live audio and video.

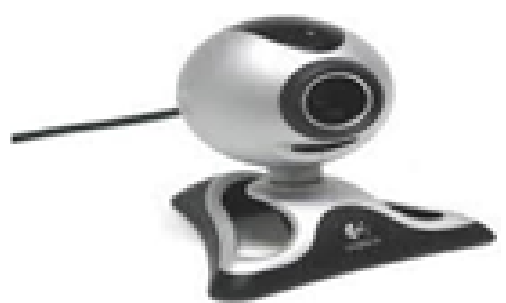

Figure 6

\section{PROPOSED WORK}

Human detection robot detects humans who are trapped in water during floods from buildings and from floating water areas. Our robot is a moving robot which will move in water. We all that it's a very difficult process to find out the people in water and very time consuming process for the rescue team.

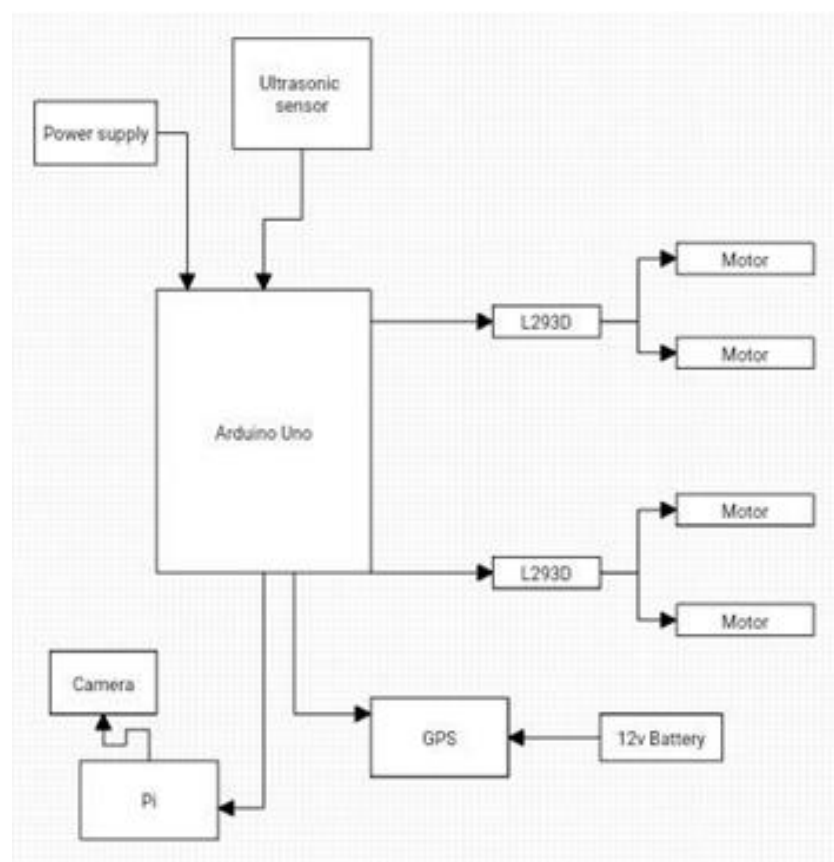

Figure 7 
A camera is fixed for capturing the images. when a human is detected a message containing the location of people where they are trapped will be send to rescue team it automatically move by help of sensor and detection occurred. will tracks the exact location. The components used for this are Arduino uno, GPS module, DC motor L293D motor driver IC ,ultrasonic sensor, Rasperry pi, Power supply, Camera and 12 Volt battery.

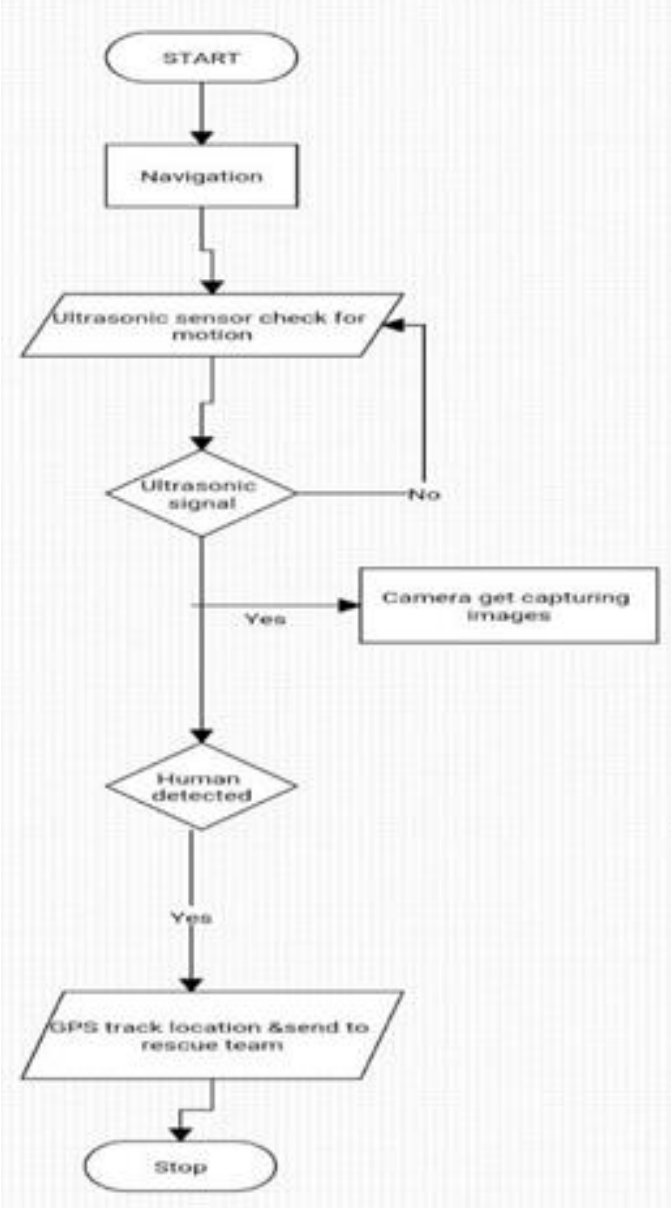

Figure 8: Flow Chart.

\section{Algorithm}

- $\quad$ Setup the baud rate 9600 and bit rate 4800 .

- Now set a loop which takes the following steps

- Start navigation.

- Motion is checked by the ultrasonic sensor.

- If the signal is received, camera captures the picture. Otherwise it repeats the above step.

- GPS module tracks the latitude and longitude of location

- Location is sent to rescue team.

- Stop navigation. 


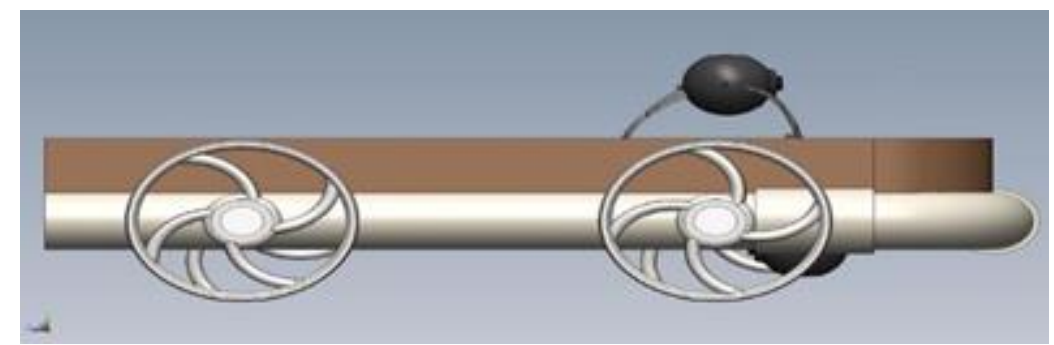

Figure 9: Right Side View.

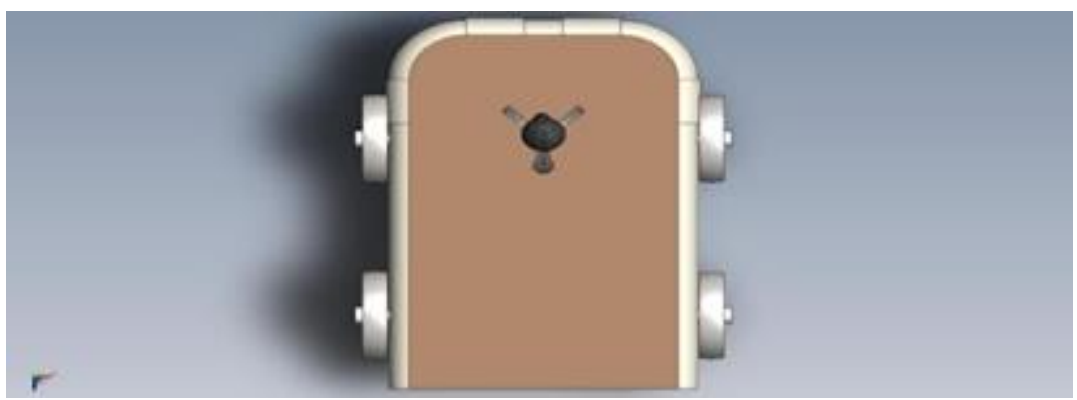

Figure 10: Top View.

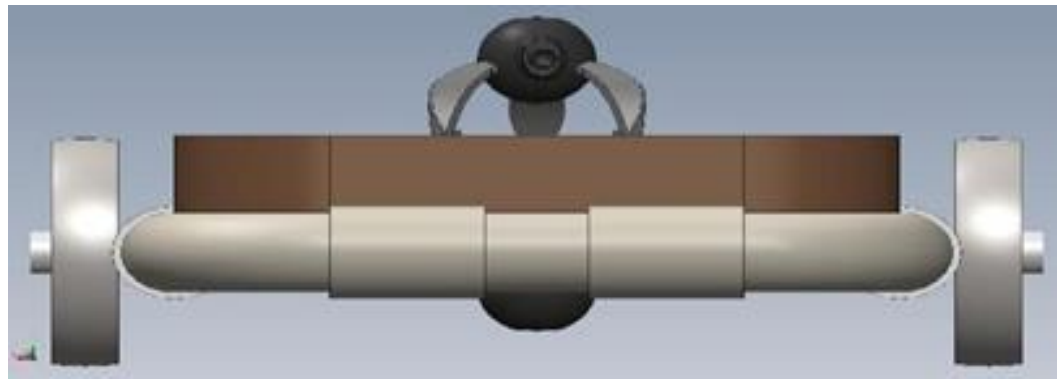

Figure 11: Front Side View.

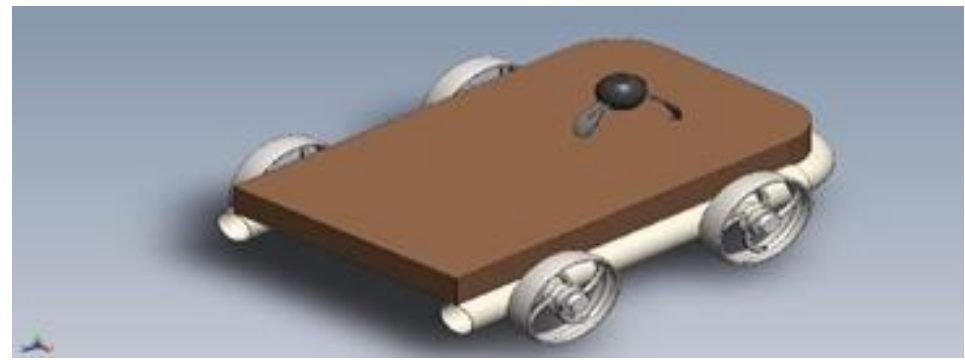

Figure 12: Isometric View.

\section{EXPERIMENTAL TESTING AND RESULTS}

The proposed device was successful in achieving its outcome as a lifesaver of people and also for the rescue team. Their future scopes with more advanced technology are still under consideration but the initial prototype is good enough in achieving its prime motive. Using Rasperri pi and GPS will help to identify humans and track the locations of trapped persons to rescue team.

The robot will move in water and ultrasonic sensor is used. By the help of sensor it will move automatically. A raspberry pi is used for image detection. When we start the navigation, Ultrasonic sensor will check for motion. And when it receives an ultrasonic signal. Then latitude and longitude of the location will track by GPS module and the particular location will be sent to the raspberry pi. And the message is sent to rescue team. 


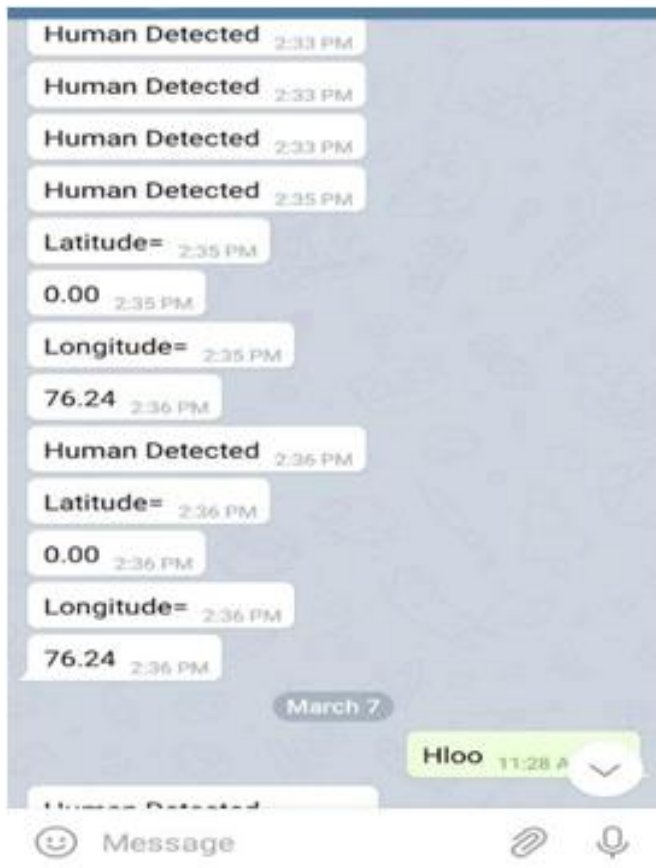

Figure 13

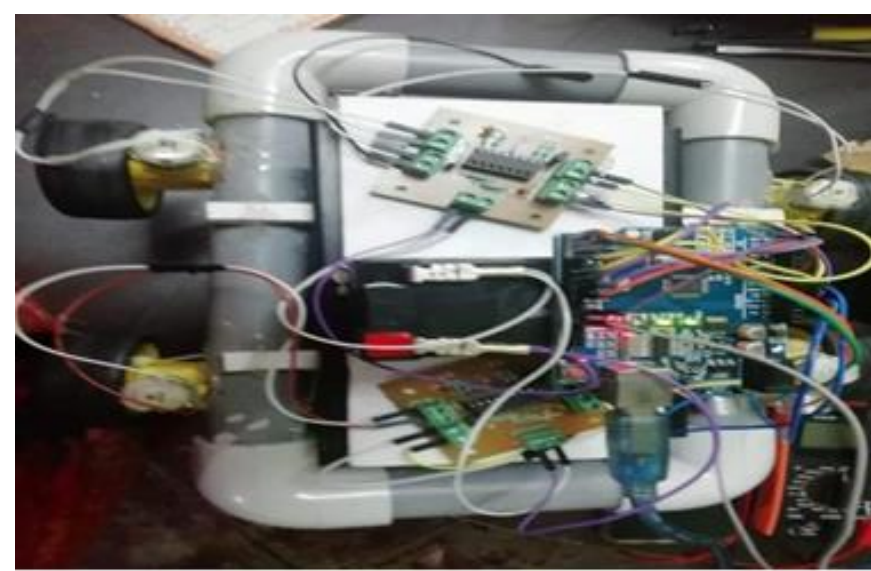

Figure 14

\section{DISCUSSION AND CONCLUSIONS}

The project proposes an automatic human detection system in water that moves in the dangerous area and it identifies the people who get injured and it performs the rescue system operations. By the timely detection injured people's valuable life can be saved without the need of a huge rescue team. It is very useful in time of flood to detect and helps the injured people to save their lives by doing the rescue system operations. It takes only less time to save the people without the need of a huge rescue team.

\section{FUTURE SCOPE}

Human detection robot has a very great future scope as the disasters like flood becoming increasing every year. During these situations mobile robot will be a great requirement. During heavy flood the trapped people can be sensed fastly. And it will help the rescue operators. This will be user friendly and advanced in technology. This will be very helpful for tracking the location and people who are trapped under water. 


\section{REFERENCES}

1. P. Govindhan, Reuben Babuji Kuruvilla, D. Shanmugasundar, M. Thangapandi: "Human Detecting Aqua Robot using PIR Sensors", "' International Journal of Engineering Science and Computing(IJESC) ", Volume 7 Issue No.4 April 2017.

2. Trupti B. Bhondve, Prof. R Satyanarayan, Prof. Moresh Mukhedkar: "Mobile Rescue Robot Human Body Detection in Rescue Operation of Disaster", "'International Journal of Advanced Research in Electrical, Electronics and Instrumentation Engineering”, Vol. 3,Issue 6,June 2014.

3. N. Anju Latha \& B. Rama Murthy, “GSM Based Rain Fall Detector Using Arduino “, International Journal of Electronics and Communication Engineering (IJECE), Vol. 5, Issue 3,pp. 11 -16

4. Mritunjay Ojha, Sheetal Mohite, Shraddha Kathole \& Diksha Tarware, "Microcontroller Based Automatic Plant Watering System”, International Journal of Computer Science and Engineering (IJCSE), Vol. 5, Issue 3,pp. 25-36

5. Mittika Ukey, Sonam Gupta, Bhagyashali Masane, Chanchal V. Dahat: “Alive Human Detection Robot in Rescue Operation”, "International Journal of Advanced Research in Electronics and Communication Engineering(IJARECE)”, Volume 5, Issue 3, March 2016.

6. Prachi More, Sudhish Surendran, Sayali Mahajan \& Saurabh Kumar Dubey, "Potholes and Pitfalls Spotter “, IMPACT: International Journal of Research in Engineering \& Technology (IMPACT: IJRET), Vol. 2, Issue 4, pp. 69-74

7. S.K.S. Yadav, “Customer Relationship Management is the Need of Today” BEST: International Journal of Humanities, Arts, Medicine and Sciences (BEST: IJHAMS), Vol. 4, Issue 2, pp. 107-116 